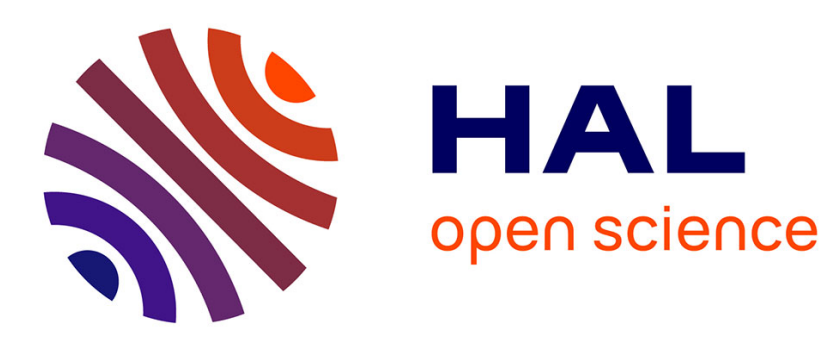

\title{
Carousel Instability in a Capacitively Coupled RF Dusty Plasma
}

\author{
Maxime Mikikian, Lénaïc Couëdel, Yves Tessier, Laifa Boufendi
}

\section{To cite this version:}

Maxime Mikikian, Lénaïc Couëdel, Yves Tessier, Laifa Boufendi. Carousel Instability in a Capacitively Coupled RF Dusty Plasma. IEEE Transactions on Plasma Science, 2011, 39, pp.2748. 10.1109/TPS.2011.2155675 . hal-00612848

\section{HAL Id: hal-00612848 \\ https://hal.science/hal-00612848}

Submitted on 3 Nov 2011

HAL is a multi-disciplinary open access archive for the deposit and dissemination of scientific research documents, whether they are published or not. The documents may come from teaching and research institutions in France or abroad, or from public or private research centers.
L'archive ouverte pluridisciplinaire HAL, est destinée au dépôt et à la diffusion de documents scientifiques de niveau recherche, publiés ou non, émanant des établissements d'enseignement et de recherche français ou étrangers, des laboratoires publics ou privés. 


\title{
Carousel Instability in a Capacitively-Coupled RF Dusty Plasma
}

\author{
Maxime Mikikian, Lénaïc Couëdel, Yves Tessier and Laïfa Boufendi
}

\begin{abstract}
Rotating plasma spheroids are observed in a capacitively-coupled radio-frequency (ccrf) discharge containing grown dust particles. These plasma spheroids are regions of slightly enhanced emission that rotate along the electrodes circumference. This effect is not systematically observed and when it occurs, the number and speed of the spheroids can vary with the discharge parameters. These spheroids have been evidenced by using high speed-imaging.
\end{abstract}

Dust particles can be grown inside a plasma by gas phase reactions [1-3] that lead to high densities of submicron dust particles. These particles acquire a negative charge and when the global charge they represent is no more negligible compared with the electron density, a wide variety of low frequency instabilities are observed. They follow the dust particle growth [4-6] or concern the void region often present in the center of dust clouds. In this last case, the void size oscillates with a strong nonlinear behavior (heartbeat [7-9]). Another type of instability connects these two effects and corresponds to void size oscillations induced directly by the growth of a new dust generation inside the void $[10,11]$.

In this paper, we report on the observation of another kind of plasma instability consisting in the rotation of plasma spheroids along the circumference of the electrodes in a capacitively-coupled RF discharge. Due to this characteristic motion, we named this behavior the "carousel instability".

Experiments are performed in the PKE-Nefedov reactor where a low-pressure $(\sim 1 \mathrm{mbar})$ argon plasma is produced in a ccrf discharge (electrode diameter $4 \mathrm{~cm}$, separation $3 \mathrm{~cm}$ ). The plasma sputters a polymer layer deposited on the electrodes, injecting molecular precursors in the gas phase. It gives birth to the growth of dust particles with a final size of about a few hundreds of nanometers after several minutes. The typical instability frequency is around a few tens of $\mathrm{Hz}$ and in order to analyze the dust cloud dynamics or the plasma emission, a high-speed camera is required.

The images shown in Fig. 1 have been obtained by recording the plasma emission at 1789 frames per second during dust particle growth. Fig. 1(a) is the raw image with a poor contrast but plasma spheroids can be detected close to both electrodes (one of them is marked). In order to better reveal these plasma spheroids, the image has been filtered notably by subtracting a reference image and by using false colors [Fig 1(b)]. Five plasma spheroids are thus clearly evidenced in front of each electrode and the position of one of them is marked. They seem to follow the electrode edges and rotate clockwise. Figs. 1(c)-(e) follow Fig. 1(b) and they evidence the successive positions of the plasma spheroids. In these figures, positions 2, 3 and 4 of the spheroid marked in Fig. 1(b) are indicated. In Fig. 1(e) the 5 plasma spheroids are well evidenced as the ones in the foreground are not hiding those in the background. Each plasma spheroid is indicated by a letter. Fig. 1(f) is the superimposition of 8 successive frames [the first four positions are the ones shown in Figs. 1(b)-(e)]. A different color is used for each frame and positions 1 and 8 of the spheroid labeled $\mathrm{c}$ are indicated.

The number of spheroids and their speed can vary with the applied rf power. This dependence is currently under investigation. In the present case, a typical speed of about a few meters per second has been measured. It gives a typical frequency of about $45 \mathrm{~Hz}$ and a spheroid needs around $22 \mathrm{~ms}$ for completing its rotation around the electrode. The spheroids of the bottom electrode are not exactly in front of those of the top electrode and some small discrepancies in their respective motion have also been observed. In some conditions, spheroids are only present above the bottom electrode. The exact nature and origin of these spheroids are currently undetermined. It is not possible to conclude if they are only constituted of plasma or of plasma and dust particles, even if the last hypothesis is highly probable. The influence of the dust cloud on the existence and characteristics (number speed) of these spheroids still needs to be clarified.

In this paper, we evidenced an instability occurring in a dusty ccrf discharge and consisting in the rotation of plasma spheroids. The study of this carousel instability can reveal new aspects of the dust-plasma interaction. On the esthetical point of view, this motion transforms the discharge into a carousel of light.

Manuscript received; revised .

M. Mikikian, Y. Tessier and L. Boufendi are with the GREMI, UMR6606, CNRS/Université d'Orléans, 14 rue d'Issoudun, BP6744, 45067 Orléans Cedex 2, France (e-mail: maxime.mikikian@univ-orleans.fr)

L. Couëdel is with the GREMI, UMR6606, CNRS/Université d'Orléans, 14 rue d'Issoudun, BP6744, 45067 Orléans Cedex 2, France and also with the Max Planck Institut für Extraterrestrische Physik, Giessenbachstrasse, 85740 Garching, Germany

The PKE-Nefedov chamber has been made available by the Max-Planck-Institute for Extraterrestrial Physics, Germany, under the funding of DLR/BMBF under grants No.50WM9852.

Publisher Identifier S XXXX-XXXXXXX-X 

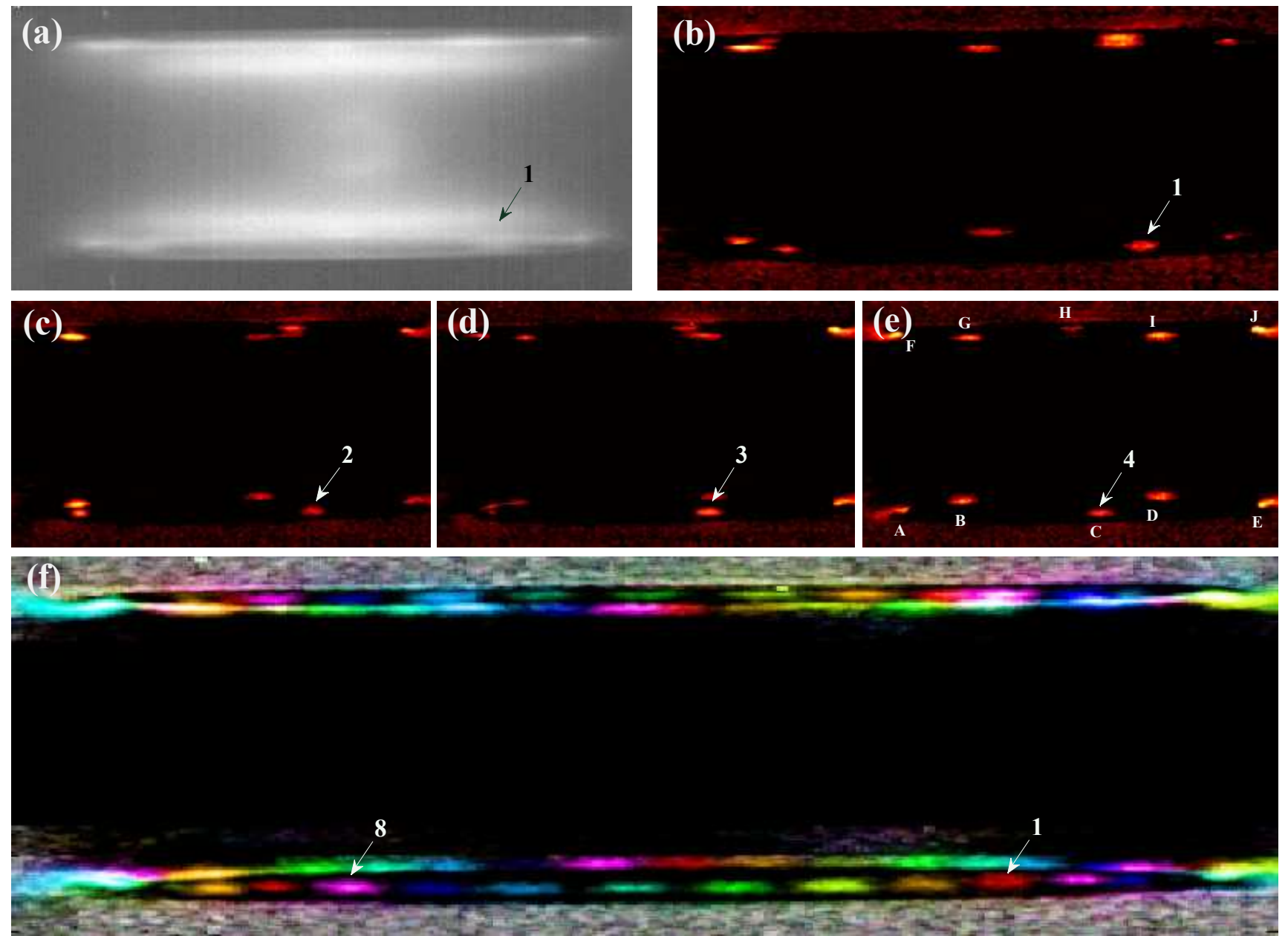

Fig. 1. Carousel instability in a ccrf argon plasma containing grown dust particles. Images of the plasma emission have been obtained with a high-speed camera. (a) Raw image of the plasma emission. The two disk-shaped electrodes are observed on the top and bottom parts. (b) Same image in false colors after filtering and subtracting a reference frame. Five plasma spheroids are observed near each electrode. They are labeled in (e). Position 1 of spheroid $\mathrm{c}$ is marked. (c)-(e) Successive frames revealing the clockwise rotation of the spheroids. Successive positions $(2,3,4)$ of the spheroid c are marked. (f) Superimposition of 8 frames using a different color for each frame. $1^{\text {st }}$ (red) and $8^{\text {th }}$ (pink) positions of spheroid c are indicated.

\section{REFERENCES}

[1] J. Berndt et al., "Some Aspects of Reactive Complex Plasmas", Contrib. Plasma Phys. 49, 107 (2009)

[2] M. Mikikian, M. Cavarroc, L. Couëdel, Y. Tessier and L. Boufendi, "Dust particles in low-pressure plasmas: Formation and induced phenomena", Pure Appl. Chem. 82, 1273 (2010)

[3] V. Massereau-Guilbaud, J. Pereira, I. Géraud-Grenier and A. Plain, "Influence of the power on the particles generated in a low pressure radio frequency nitrogen-rich methane discharge", J. Appl. Phys. 105, 033302 (2009)

[4] M. Mikikian, M. Cavarroc, L. Couëdel and L. Boufendi, "Low Frequency Instabilities during Dust Particle Growth in a Radiofrequency Plasma", Phys. Plasmas 13, 092103 (2006)

[5] M. Mikikian, L. Couëdel, M. Cavarroc, Y. Tessier and L. Boufendi, "Plasma Emission Modifications and Instabilities Induced by the Presence of Growing Dust Particles", IEEE Trans. Plasma Sci. 36, 1012 (2008)
[6] D. Samsonov and J. Goree, "Instabilities in a dusty plasma with ion drag and ionization", Phys. Rev. E 59, 1047 (1999)

[7] M. Mikikian, M. Cavarroc, L. Couëdel, Y. Tessier and L. Boufendi, "Mixed-Mode Oscillations in Complex Plasma Instabilities", Phys. Rev. Lett. 100, 225005 (2008)

[8] M. Mikikian, L. Couëdel, M. Cavarroc, Y. Tessier and L. Boufendi, "Threshold phenomena in a throbbing complex plasma", Phys. Rev. Lett. 105, 075002 (2010)

[9] S.K. Zhdanov et al., "Auto-oscillations in complex plasmas", New J. Phys. 12, 043006 (2010)

[10] M. Cavarroc, M. Mikikian, Y. Tessier and L. Boufendi, "Instabilities during the growth of dust successive generations in silane-based plasmas", Phys. Plasmas 15, 103704 (2008)

[11] L. Couëdel, M. Mikikian, A.A. Samarian and L. Boufendi, "Self-excited void instability during dust particle growth in a dusty plasma", Phys. Plasmas 17, 083705 (2010) 